Marquette University

e-Publications@Marquette

9-1-2006

\title{
Order Lead-Time Improvement Following Enterprise Information Technology Implementation: An Empirical Study
}

Mark Cotteleer

Marquette University, mark.cotteleer@marquette.edu

Elliot Bendoly

Emory University

Published version. MIS Quarterly, Volume 30, No. 3 (September 2006): 643-660. Permalink. (C 2006 University of Minnesota, Management Information Systems Research Center. Used with permission. 


\section{ORDER LEAD-TIME IMPROVEMENT FOLLOWING ENTERPRISE INFORMATION TECHNOLOGY IMPLEMENTATION: AN EMPIRICAL STUDY ${ }^{1}$}

By:

\author{
Mark J. Cotteleer \\ Marquette University \\ P.O. Box 1881 \\ Milwaukee, WI 53201 \\ U.S.A. \\ mark.cotteleer@marquette.edu \\ Elliot Bendoly \\ Emory University \\ 1300 Clifton Road \\ Atlanta, GA $30322-2710$ \\ U.S.A. \\ Elliot-Bendoly@bus.emory.edu
}

\begin{abstract}
This paper investigates the influence of enterprise systems implementation on operational performance. The work extends the literature on enterprise systems by focusing on changes in process dynamics as a source for ongoing firmlevel performance improvement. A case discussion of Tristen Corporation, a firm that implemented ERP and subsequently experienced benefits through gains to its continuous improvement efforts, is examined in light of theorized impacts of such implementations on process dynamics. Analyses of longitudinal data suggest that performance along a key metric motivating the ERP initiative (i.e., order fulfillment lead-time)
\end{abstract}

\footnotetext{
${ }^{1} V$. Sambamurthy was the accepting senior editor for this paper. Ken Boyer, Sanjay Gosain, and Namchul Shin served as reviewers.
}

showed a significant improvement immediately after system deployment. The data further suggest that the system implementation gave rise to an ongoing trend of performance improvement, in contrast to a stable performance trend prior to go-live.

Keywords: Enterprise resource planning, visibility, validity variability reduction, continuous improvement, organizational learning, empirical research

\section{Introduction}

Enterprise systems are one of the most important information technology categories to emerge in the last decade (Davenport 2000). Best represented by enterprise resource planning (ERP) applications, such systems are software products that support the wide array of work processes on which firms rely to conduct their day-to-day business. Among the business processes commonly supported by enterprise systems are order management, finance, manufacturing, and logistics (Davenport 1998; Escalle and Cotteleer 1999). Enterprise systems typically link these processes in the context of multiple geographically distributed operating sites (Markus et al. 2000).

ERP and other enterprise systems are important from an economic perspective because they have attracted large investments by many firms. The more than $\$ 47$ billion invested in such systems in 2001 (AMR 2001) does not include the billions of additional dollars of investment in computer hardware and services required to support these 
applications (Mabert et al. 2000; Willcocks and Sykes 2000). Reports further suggest that nearly 75 percent of U.S. manufacturing firms have made, or are considering making, an ERP investment (Mabert et al. 2000). SAP, a leading enterprise systems vendor, reported that in 2001 it counted 17,500 organizations in more than 120 countries as customers (SAP 2001).

Enterprise system implementations are representative of dramatic change efforts within firms. Many experience unprecedented periods of tumult as they grapple with the replacement of core information systems across the distributed geographies in which they do business. More than 90 percent of firms that implement ERP do so for multiple process areas (Hitt et al. 2002), and more than 40 percent change over to new systems and processes, termed a "big bang" implementation, in a single step (Mabert et al. 2000). Given the magnitude of economic and organizational investments involved in implementation, efforts to understand the influence of such systems on firm performance promise to make significant contributions.

Recent empirical research has already suggested that implementing firms realize productivity and market capitalization benefits (Hitt et al. 2002), and studies of operational performance suggest that ERP positively influences performance over time (McAfee 2002). This paper further examines the impacts of these systems by investigating the shifts in organizational learning dynamics facilitated by their use. Drawing on theory from the operations management domain and the concept of continuous improvement, both case examination and quantitative analysis are used to demonstrate the nature of such ERP-driven learning benefits.

The rest of the paper proceeds as follows. The next section presents an overview of some of the literature that is relevant to a discussion of enterprise systems and their influence on operational performance. The context and data used in the study are then described. The subsequent section explains the analytic model used and relates the results of the statistical analysis. A discussion of the analysis offers further depth in the explanations for the results observed, outlines potential implications, and discusses limitations of the study that suggest areas for subsequent research.

\section{Related Research}

Enterprise systems hold the potential to augment performance by promoting commonality, improving functionality, enhancing visibility, and ultimately fostering learning across the operations of an organization (Chen 2001; Davenport 2000; Jacobs and Bendoly 2003; Mabert et al. 2000; McAfee 2002). Findings of an emerging body of empirical research that investigates the influence of enterprise systems on firm-level performance suggest that ERP implementation correlates with improvement across multiple measures, including productivity and Tobin's q (Hitt et al. 2002), and operational performance (McAfee 2002).

Although firm-level trends can be observed and speculated about, quantitative empirical research has yet to offer a wellaccepted explanation for the processes that give rise to firmlevel performance dynamics following large-scale enterprise systems initiatives. This may be due in part to the multiplicity of factors that potentially contribute to such phenomena. This proliferation of factors has traditionally made the linkage of theoretically anticipated benefits and firm-level performance changes difficult to verify (Cotteleer 2006; Kauffman and Kriebel 1988; Mukhopadhyay and Cooper 1992).

One practical approach to benefits assessment suggests the examination of similar effects at lower operational process levels within the distinct business units that comprise the enterprise. Prior studies recommend that research extrapolate upward to higher level performance changes given knowledge of the relative roles these units play (Banker and Kauffman 1988; Banker et al. 1990; Kling 1991). Although the impact of enterprise systems is characterized as extending across multiple sites (Austin and Cotteleer 2001; Markus et al. 2000), empirical insight into process-driven performance dynamics at individual locations has thus far been limitedby extension limiting the completeness of our understanding of the true impacts of these initiatives. This study addresses this limitation by explicitly adopting a process perspective that allows for a logical linkage between case evidence of business unit operational details and firm-wide performance on a key metric that drove the ERP initiative from the onset.

Fortunately, theoretical frameworks are available for considering the processes through which ERP implementation affects site-level, and ultimately firm-level, operational performance. One such framework draws on the theory of swift, even flow (Schmenner and Swink 1998) to delineate process characteristics affected by ERP deployment (Bendoly 2001; Bendoly and Kaefer 2004). From a general standpoint, the theory of swift, even flow is grounded on a number of wellestablished laws of operational dynamics. One of these is the law of variability (from queuing theory), which outlines the benefits to process-throughput that reductions in processvariability can provide (see, for example, Conway et al. 1988; Kannan and Palocsay1999; Powell and Schulz 2004). 
Efforts to reduce operational variability are often associated with control and standardization of business processes. In ERP contexts, this is made possibly largely by the process templates that vendors embed in packaged applications (Scheer and Habermann 2000). These templates incorporate vendor-embedded knowledge about "best practice"industry-proven approaches to carrying out common business processes (Austin and Nolan 1998; Davenport 2000; Upton and McAfee 2000). Consistent with the view of technology as a key enabler of knowledge transfer and organizational learning (Epple et al. 1996), from an operational standpoint such well-structured (Davenport 2000) and often difficult to circumvent (Bendoly and Cotteleer 2004) protocols make variability reduction almost unavoidable. Firms, therefore, have good reason to expect that ERP deployment can drive process improvements. Indeed, the deployment of ERP is often described as motivated by the firm's desire to reduce such variation through the standardization of business process (Austin and Cotteleer 1999).

Perhaps more important to the theoretical argument for process benefit, swift, even flow builds on the law of variability to suggest additional organizational learning phenomena. A second dimension of the theory incorporates Goldratt's (1992) law of bottlenecks. According to this law, significantly measurable process improvement may be difficult to achieve on an ad hoc basis. Although a system may benefit from an indiscriminant, yet pervasive, reduction in variability, superior results are to be expected only when variance reduction efforts target key process bottlenecks. Through the thoughtful identification and targeting of specific elements of a process, the whole system can reap the benefit of adjustment, standardization, and automation.

Swift, even flow merges Goldratt's views on bottleneck management with the law of variability to suggest that intelligent efforts to facilitate (e.g., by variability reduction at bottlenecks) the flow of intermediate inputs (e.g., orders-inprocess) within a system will increase the output of that system. Therefore, the joint presence of both bottleneck (limiting subprocess) awareness and variability reduction capabilities is critical to the implications of the totality of theory. In isolation, these mechanisms can be entirely ineffective. To paraphrase Bendoly and Schoenherr's (2005) application of this theory to an IT-benefit context, only mechanisms that enable both bottleneck awareness and variability reduction ensure a means for deriving observable performance gains in process flow. Given that ERP applications are characterized as providing increased visibility and standardization (Mabert et al. 2000; McAfee 2002) and are thus well equipped to facilitate process-bottleneck identification and variability reduction, it follows that firms that deploy ERP systems have reason to expect that the mechanics of swift, even flow may enable ongoing process improvement.

More general, yet complimentary, process-focused frameworks also exist to assist in anticipating ERP-driven performance dynamics across multiple sites (Lee 2000). A notable example is the framework by Mooney et al. (1995) for delineating types of benefits accrued at primary and secondary levels of process consideration. The benefit-mechanism classifications described in this framework include automational, informational, and ultimately transformational effects, serving as a superset of Davenport's (1993) nine IT benefits. Mooney's framework juxtaposes these benefit types against the sequential process distinction of "operational" and higher-level "managerial" performance. The general implication is that operational improvements translate into managerial benefits by virtue of the organizational transformations they catalyze. This conclusion is consistent with those of related works (see, for example, Banker et al. 1990; King and Kraemer 1989; Yusuff 2004).

Most relevant to the current discussion, these benefitsmechanism classifications (automational, informational and transformational) are integrally tied to the benefit-targets (e.g., variability at bottlenecks) of swift, even flow as it has been applied to ERP contexts. As such, a hybrid application of terminology from these two frameworks is helpful in outlining arguments for operational benefits arising from ERP initiatives (see Figure 1).

Specifically, in any application of swift, even flow theory, visibility of bottleneck indicators (e.g., work build-ups) is critical to bottleneck identification as well as to associated efforts at reducing variability targeted at such bottlenecks (Schultz et al. 1998). However, where physical indicators (i.e., quantities of materials) are often present in manufacturing processes, other aspects of order processing operations (i.e., backlogged order entries) are predominantly informational and best identified through the assistance of associated information systems. This is where informational visibility provided by ERP systems could best complement the automational capabilities of these architectures, in accordance with Mooney et al.'s terminology. Informational capabilities provided by ERP help managers "see" bottlenecks in information-based processes. Automational capabilities inherent in ERP systems provide structure for these same processes, reducing variability and promoting swift, even flow. These benefits should be observable in operational performance measures that specifically capture the dynamics of swift, even flow (e.g., throughput as presented by fulfillment lead-times). As a result, and particularly for firms focused on such performance measures, we specifically outline our first hypotheses as follows: 


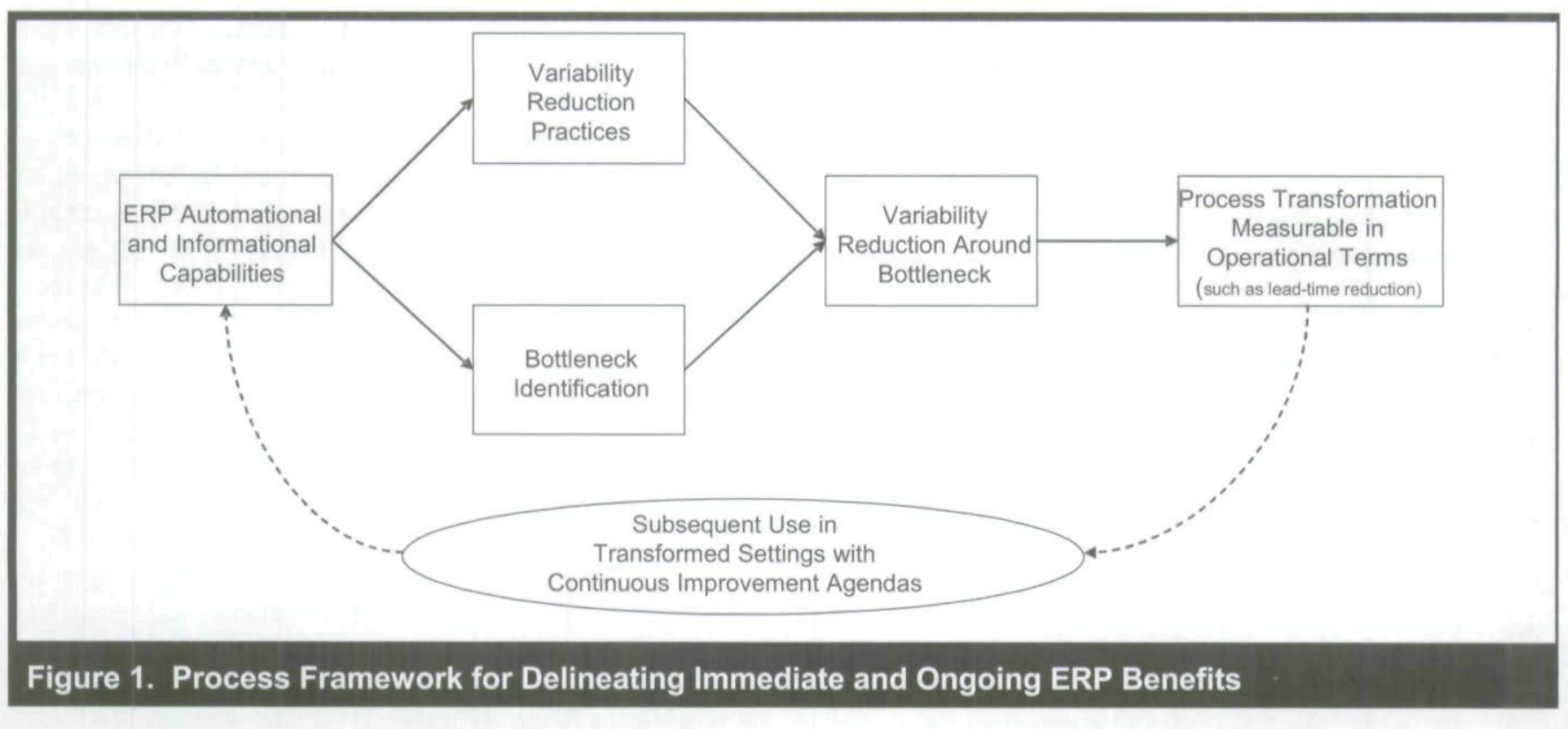

H1: The implementation of enterprise systems (e.g., ERP) will result in near-term improvements in the operational performance (e.g., order fulfillment lead-time) of the firm.

Since process changes tend to extend the implementation timeframe, the opportunity exists for additional information gains to yield ongoing process change and performance improvement (Zuboff 1988). Firms dedicated to continuous improvement philosophies are expected to continue to seek out new bottlenecks as others are eliminated (Goldratt 1992). In fact, this cycle of learning and improvement is the very essence of continuous improvement embodied by both Goldratt's five-step approach and the classic Deming cycle, a hallmark of the quality management movement (Reid 1992). Given the aforementioned assumed capabilities of these systems, firms equipped with ERP can be expected to use early improvements as launching points for further bottleneck identification, variability reduction, and improvement, provided continuous improvement is in fact an established norm in their organizational culture.

The logic behind the improvement cycle and its antecedents promotes the expectation that ERP use can trigger ongoing improvement cycles (as characteristic of learning effects discussed throughout the literature) that might not exist absent the enabling capabilities suggested by swift, even flow theory. In the terminology of Mooney et al., ERP is expected to provide both an initial transformation and a learning dynamic that persists over time. In fact the ongoing data acquisition capa- bilities of ERP architecture, in conjunction with the greater visibility and standardization (variability reduction) mechanisms it provides, reinforce the notion of the enterprise system as an evolving resource that is well suited to an organization concerned with ongoing learning and process improvement. Therefore, once an ERP architecture is deployed, one should anticipate observable ongoing improvement trends through time and experience with the system, provided sufficient account is taken of variance in other critical operational controls upon which these performance metrics are dependent. Along with past literature that has suggested IT impacts on process-focused organizational learning dynamics (see, for example, Davidow and Malone 1992; Gerwin 1993; Stein and Zwass 1995; Zhu et al. 1997), this learning-dynamic extension of swift, even flow, assisted by the Mooney et al. framework, provides the impetus of our second hypothesis.

\section{H2: Ongoing learning effects (e.g., continuing im- provements in order fulfillment lead time over time) should be observable and significant over an extended period following enterprise systems deployment.}

In posing these two hypotheses, this paper takes a discernibly process-oriented viewpoint toward improvements emerging in the context of an ERP implementation. In doing so, the work is positioned as an extension of the IS organization research stream outlined by Banker and Kauffman (2004) and addresses their call for alternative perspectives by incorporating operational shifts into a more complete view of implementation performance dynamics. 


\section{Context Specification and Data}

This study relies on two complementary sources of information for use in assessing the process impacts of an ERP initiative. The first facilitates an understanding of the context within which implementation occurred. This source consisted of document reviews as well as interviews with managers, project participants, and system users. Interviews were semistructured and included questions about system development, training, deployment, and post-implementation support. These interviews provide the basis of our case documentation, subsequent model justification, and concluding discussion.

The second source of information consisted of the firm's records of operational data collected over the duration of the ERP initiative studied. This data served as the foundation for the quantitative analysis associated with this research.

\section{Tristen Corporation: A Case Study}

The focus of this study was an ERP deployment at Tristen Corporation, a U.S.-based, $\$ 4$ billion producer of peripheral equipment for servers, desktop PCs, and other computerized devices. Tristen employed nearly 10,000 people at more than 20 sales and manufacturing sites worldwide.

In the late 1990s, Tristen management began to perceive a trend toward commoditization of the company's core products. In response to this trend, corporate strategy shifted to emphasize delivery of products with "high value-added" over technological innovation. High value-added incorporated a dual emphasis on cost leadership and superior customer service. Given the rapid pace of change in the industries it served, Tristen viewed order fulfillment lead-time as a critical component of customer service and supported a culture of continuous improvement aimed at finding new ways to increase their competitiveness on this issue. Order lead-time was also crucial to firm performance from an accounting perspective, as it reduced the chances of Tristen getting caught with newly obsolete inventory.

Tristen served its core markets through three manufacturing/ distribution centers (MDCs), each of which supported one of its operating regions: North America, Europe, and Asia. Product orders were gathered at sales offices scattered throughout an operating region and forwarded to the respective MDC for scheduling and commitment. Once committed, product availability was signaled back to the sales office for confirmation to the customer (Figure 2 depicts the order process flow).
For the most part, Tristen manufactured products to forecast but held them in a semi-finished state within each region in anticipation of future demand. Final configuration and testing of products was completed during order fulfillment.

During this time, management perceived Tristen's continued efforts to better manage fulfillment as limited by inability to respond more quickly to customer order specification, configuration, and quality assurance needs. Since the efficiency and effectiveness of each of these activities was ultimately bundled into lead-time performance, each was viewed as a critical area for improvement. Examples of difficulties were manifold. For instance, the need for a sales office to confirm every order through its respective MDC could generate significant order delays. The process often included repeated telephone and fax contacts between customers, sales offices, and the MDC in order to secure product commitments. In the presence of a near total lack of inventory and production plan visibility, the ordering commitment subprocess could take upwards of one week. Furthermore, logistics personnel were required to manually track inventory across MDCs. Depending on the time and location of a contact with Tristen, a customer might receive different lead-time commitments for the same product order.

Central to Tristen's challenges was a lack of financial and operating data visibility across the firm. The information systems on which the three regions relied had been in place for more than 15 years and were not integrated with one another, making enterprise-level transactions difficult. Tristen managers concluded that new information systems were needed to enable greater visibility of problem sources, improve fulfillment lead-time, and thus make additional competitive strides in customer service. A critical component of these systems would be "available-to-promise" (ATP) functionality. "We recognized that we needed the ability to commit to orders in real time from anywhere in the world," remarked one manager. Added another,

From the operations side it was essentially about
available-to-promise and being able to respond
faster. The reason we wanted worldwide ATP was
that many of our customers are global. So, for
example, a customer has operations in North
America, Europe, and Asia. They expect each
operation to be treated the same. Instead, [at the
time] the different regions were getting different
levels of service.

The need for ATP, standard protocols that spanned the firm's operating units, and other operational improvements led Tristen to establish an enterprise systems initiative. Part of 


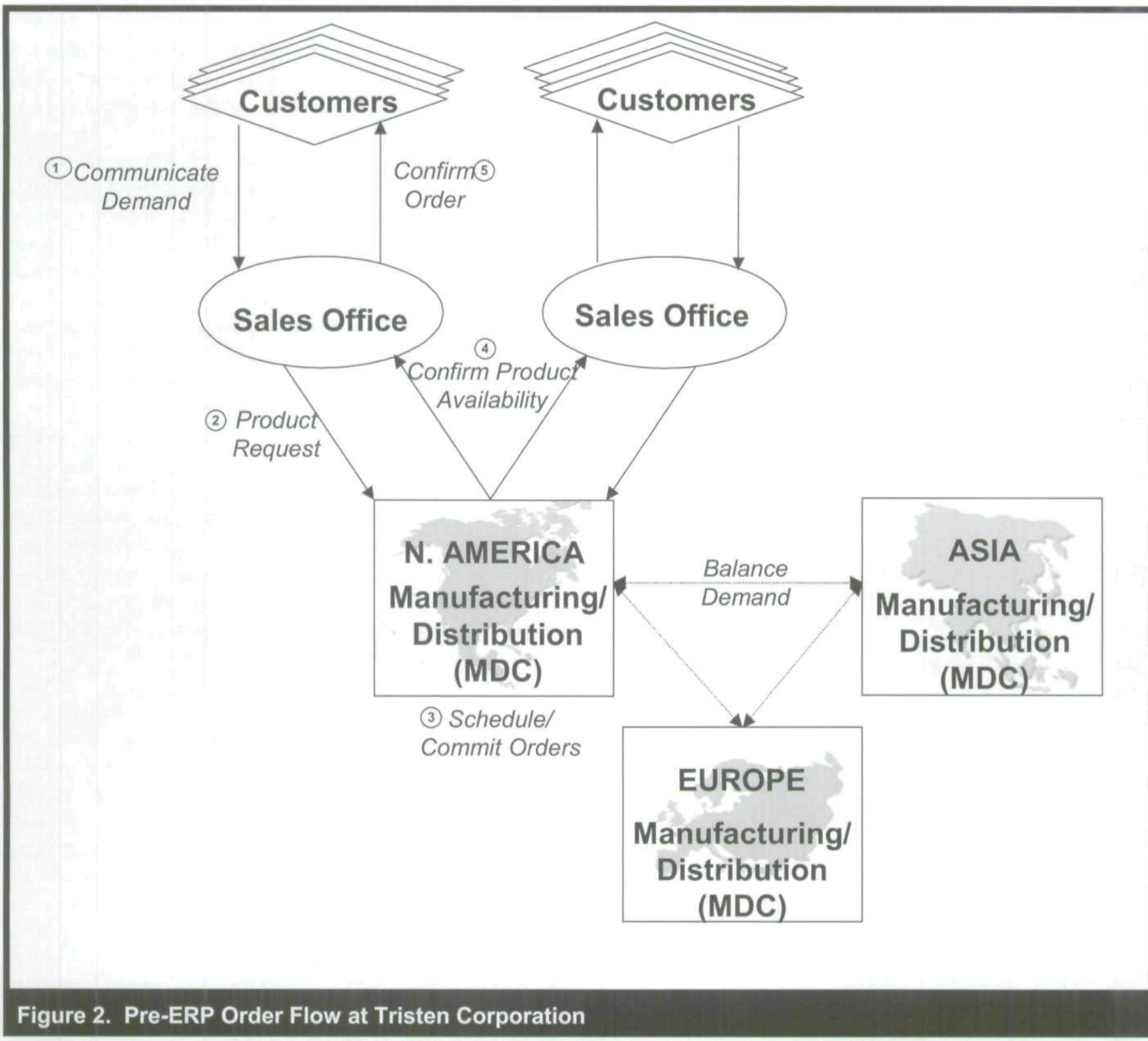

the mission of this initiative was "partner [ing] with customers to define, monitor and meet their evolving business needs for product availability, delivery, and integrated inventory management."

Tristen chose a leading ERP application suite to replace its aging legacy systems. In defining a deployment approach, it held itself to three standards: minimal package customization; minimal business process change; simultaneous ("big bang") implementation of all processes at all locations. In situations in which the first two standards conflicted, the bias of the implementation team was to accept the business process as it worked in the unmodified software. Reflected one manager, "So what's the leap to understand that you ought to do the process the way the software package does it? If the package does it at least as well as or better than the company currently does then follow the package instead of modifying the software." 2

\footnotetext{
${ }^{2}$ In rare cases where Tristen managers felt that the software did not match an important need of the business modifications were attempted. Most significant among these was the development of functionality to allow for financial processing in multiple currencies. No significant modifications to order management or logistics functionality were reported.
} 
Another decision made by managers of the ERP implementation was to locate all aspects of systems and process development within a single building at Tristen's North American headquarters in the United States. Project team members took up residence in the local community for the duration of the development process. Although dominated by North American personnel, the implementation team included representatives from other global sites - notably, each of the other MDCs. Managers believed that this move maximized the potential for interaction among project team members. Emphasized one manager,

\section{Collocation was absolutely critical, absolutely key to this project because you got the interface in the hallway, you got the, "Hey, Bill, how do you do this?" and Bill would come over and sit down and show you.}

Firm preparations for implementation also included stationing key project team members in each of the operating regions during and immediately following ERP deployment. These highly qualified individuals, referred to as "superusers,"were well down their individual learning curves with respect to the new process and technology. Perhaps more important, these team members were also competent to rapidly resolve userissues. "There was nowhere for us to go, nowhere for us to hide," reflected one project team member. "We were going to implement this thing to work the best we knew how, and if it didn't [work], we were going to be here to fix it." Observed another team member,

\section{They had somebody who had worked on the project for more than a year and knew the software very well, so they had a sort of built-in escalation path that the other people at the site could go ask about how things worked.}

From an organizational learning perspective, these local resources represented a source of "vicarious learning" for end users in each of the regions and thus epitomized Tristen's continuous improvement philosophy. Vicarious learning is knowledge gained by others but which is available for the organization's use (Chew et al. 1991). In Tristen's case, vicarious learning was embedded in the project team members who participated in the ERP development project, training, and deployment efforts. Project managers disseminated these resources to the operating regions with the intent to help buffer them from the initial shock of implementation. Such action simultaneously facilitated the sharing of information critical to process bottleneck identification and variability reduction efforts during protocol configuration.
More importantly, from the perspective of the framework presented in Figure 1, the creation of superuser roles created an ongoing catalytic mechanism targeted primarily at reducing variability in work processing tactics post-deployment. The individuals were well placed to quickly resolve process bottlenecks and reduce wasteful processing activities as they continued to evolve down the road. In large part, the superuser role was informational, although knowledge conveyed to users was also expected to enrich and thus transform the way users approached their tasks (Zuboff 1988).

Influences from system capability also became immediately active, conferring additional operational benefits following system deployment. For example, inventory tracking transitioned from a manual to an automated process. In addition to directly improving the speed of this lead-time component activity (and thus its risk of serving as a process bottleneck), automation also provided indirect benefits by reducing error rates in the activity (and thus wasted resource hours). In doing so, it also had the potential of freeing up resources for other tasks and thus contributed in a transformational and iterative sense (à la Figure 1) to the value of the work in which users were involved.

The imposition of enterprise-wide standards provided direct and indirect benefits as well. Interface and process standards reduced variance in the execution of order specification, configuration, and quality assurance tasks. Doing so provided indirect benefits to operations planners who depend on time estimates for allocating work and establishing schedules. Ultimately such indirect informational mechanisms would make it possible to offer more precise, and typically shorter, lead-time promises to customers since the risks of missing anticipated targets were reduced.

\section{Operational Data Collection}

Selection of a dependent variable for the analysis was guided by Tristen's overall focus on order lead-time reduction. Order lead-time is defined as the elapsed time between the receipt of an order and shipment of the product to the customer. This measure has established roots as an indicator of order management and supply-chain performance, having been used in multiple studies of related phenomena (Hult et al. 2002; Mabert et al. 2000; McAfee 2002). The general importance of cycle time has been demonstrated in studies of customer service (Stalk and Hout 1990) and manufacturing performance (Hayes et al. 1988). The timeliness of customer service has also been identified as a primary reason for other IT investment (Brynjolfsson and Hitt 1996). Finally, order leadtime reduction is valuable as a source of overall business cycle 


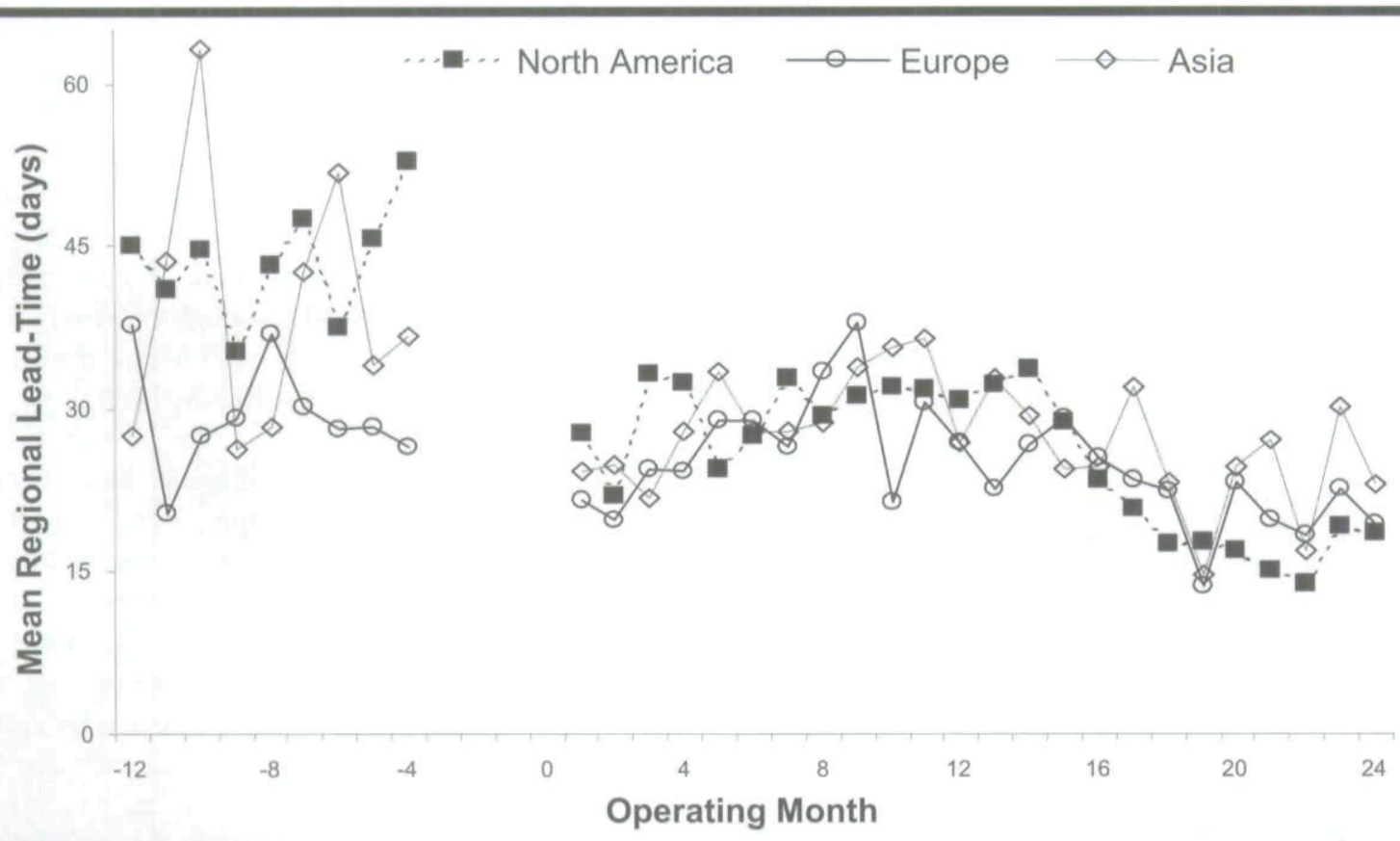

Figure 3. Monthly Aggregated Raw Lead-Time Data by Region

reduction and working capital release. For example, a oneday reduction in order lead-time was estimated to be worth approximately $\$ 11$ million in freed working capital at Tristen.

Lead-time data was collected for sales orders booked before and after ERP deployment at Tristen. Data were collected for the firm's three operating regions, all of which implemented the same ERP solution on the same date. Approximately 113,000 pre- and post-deployment order records, accounting for every order transaction during the study period, were provided by the firm. These records cover a period beginning 12 months prior to deployment and extend 24 months following deployment. ${ }^{3}$ Figure 3 summarizes this data at the month level for each of Tristen's operating regions, both prior to and following ERP deployment.

\footnotetext{
${ }^{3}$ Order transactions for the three months prior to ERP deployment are excluded to accommodate proprietary disclosure requests. Inclusion of such data was also viewed as a source of bias since at the time of ERP implementation, all outstanding orders were reentered into the new system with order dates corresponding to the first week of ERP operation. Information was thus not available on the full set of orders processed in the quarter prior to implementation (i.e., only orders that were taken and shipped prior to implementation would have been included in the data set). The first 5 days of operation following ERP deployment are also excluded as all outstanding pre-deployment records were converted to the new system with booking dates during that time.
}

In addition, the collected data accommodated the analysis of related information that enabled the sorting of transactions by operating region and classification by transaction date, order quantity, and order value.

Additional data collection supplemented the operational data set with information on Tristen's quarterly inventory levels leading up to and following ERP deployment. Inventory data was sought because of its potential to influence the findings of the study. Inventory is frequently used to buffer system shocks (Hayes et al. 1988). In the course of normal business, these shocks might take the form of unexpected fluctuations in demand or disruptions to the supply chain. In the case of preparing for ERP implementation, shocks might take the form of disruptions to business processes as employees learn to use the new information systems to execute normal business.

Field evidence suggests that Tristen managers took specific steps to create an inventory buffer to guard against initial shock of ERP deployment to its production and delivery capability. They did so by increasing inventory levels in the months prior to implementation. Since a long recognized connection between inventory levels and lead-time has been established in the operations literature (see, for example, Cattani and Souza 2002; Cheng et al. 2002; Song and Xu 1999), the inclusion of such data for the planned analysis was essential. 


\section{Modeling and Analysis}

\section{Model Form}

Specification of models and variables used in describing the performance dynamics (i.e., lead-time improvements) for this study was theoretically motivated by the extant literature on organizational learning curves (for comprehensive reviews of the learning curve literature, see Dutton and Thomas 1984 ; Yelle 1979), the dynamics proposed by swift, even flow (Schmenner and Swink 1998) and by implementation literature (e.g., McAfee 2002) relevant to the specific case studied here. Models designed to illustrate learning typically incorporate measures that capture operational scale in order to control for economies that might arise as a result of size (Adler and Clark 1991; Argote and Epple 1990; Dutton and Thomas 1984; Gruber 1992, 1994; Yelle 1979). We account for such effects by introducing the total number of orders recorded within each of the firm's operating regions on a particular day (daycount). Daily region-level averages of order quantity (units) and dollar value (value) measure scale at the order level. These variables are included to account for managers' prioritizations based on alternative measures of order size. Although exogenous and not thought to be significantly influenced by implementation plans, these controls nevertheless are viewed as potentially influencing lead-time performance from a process perspective.

A rapid reduction in inventory levels in the quarters immediately following ERP deployment is also of interest in this analysis. Although inventory data revealed a regular pattern of buildup coinciding with the end of each calendar year, inventory increases in the quarters leading up to ERP deployment were significantly larger and of longer duration. Within one year following deployment, however, both absolute and revenue-adjusted inventory levels fell by nearly 60 percent, rapidly depleting the buffer Tristen had built to support performance.

Since research has established a link between inventory availability and lead-time, the impact of these inventory dynamics represents a potentially crucial operational process effect. With specific reference to Figure 1, this process effect describes a causal sequence between implementation activities targeted at temporary bottleneck alleviation (i.e., "subordination to bottlenecks" in the terminology of Goldratt 1984), ultimately giving rise to a transformational effect on the fulfillment process (i.e., "swifter" fulfillment according to Schmenner and Swink 1998). Although this shift in policy was not intended for the long-term (as it would impose added inventory carrying costs), we felt that accounting for inventory fluctuations during the research timeframe was important to faithfully delineating these implementation-motivated effects from any other impacts of the ERP initiative.

We also include a region-level autoregressive term (leadtime $_{t-1}$ ) in recognition of the possibility that day-to-day performance may be affected by performance on preceding days. For example, if limited resources on a particular day lead to delays in order fulfillment, any backlog generated may need to be dealt with on subsequent days, creating further backlogs and possibly perpetuating a pattern of delay. Similarly, when lead-times are unusually short, resources may be free to complete orders otherwise scheduled for later fulfillment. The auto-correlated nature of this resourcefocused process sequence is not uncommon and has been the subject ongoing study (see, for example, Gudum 2002; Heuts and Deklein 1995; Zipkin 1986). The variables included in our analysis are summarized in Table 1.

A review of summary statistics for the raw data raised concern that skewness may indicate violation of normality assumptions required for data analysis. These suspicions were confirmed through the use of Shapiro-Wilk W tests for normality (Royston 1992). Tests indicated significant departures from normality $(p<.01)$ for variables used in the analysis. Box-Cox transformations (Box and Cox 1964) were performed in order to eliminate this skewness and ensure normality. The exception to this rule concerned inventory data, for which daily information was not available (i.e., it enters models as a quarterly summary). Post-transformation summary statistics for each of the variables are presented in Table 2.

Shapiro-Wilk tests confirm normality and the absence of skewness in the transformed data. We note that, following transformation, variables can now take on negative values. We further add that since transformation makes interpretation of regressions difficult, our discussion will attempt to present results as well as "untransformed" findings.

Following transformation of the variables, pairwise correlations were calculated to assess preliminary relationships between variables. These results are presented in Table 3 .

\section{Statistical Results}

Relating specifically to the context of this study, it has been proposed that the initial deployment of ERP across the firm would demark a significant shift in performance, largely due to the existence of previously unavailable system capabilities (i.e., Hypothesis 1). This hypothesis is tested using a comparison of pre- and post-deployment performance means and 


\begin{tabular}{|l|l|}
\hline \multicolumn{2}{|l|}{ Table 1. Analysis Variable Definitions . } \\
\hline Variable Name & \multicolumn{1}{l|}{ Definition } \\
\hline leadtime & $\begin{array}{l}\text { Mean elapsed time between the order booking date and the date an order is recorded as shipped to the } \\
\text { customer for a specific date and operating region. Calculated at the operating region level. }\end{array}$ \\
\hline leadtime & Mean daily region-level lead-time for the previous day. \\
\hline day & $\begin{array}{l}\text { A time index variable used to capture the number of days prior to or following ERP deployment for which } \\
\text { regional mean daily lead-time is calculated. }\end{array}$ \\
\hline day2 & The quadratic form of the time index "day". \\
\hline daycount & $\begin{array}{l}\text { The total number of order transactions processed within the operating region on the day for which } \\
\text { regional mean daily lead-time was taken. A measure of business scale. }\end{array}$ \\
\hline value & $\begin{array}{l}\text { The mean dollar value (in thousands) of the sales orders taken on a specific day in a specific region. A } \\
\text { measure of order value. }\end{array}$ \\
\hline units & $\begin{array}{l}\text { The mean number of product units (in thousands) associated with the orders taken on a specific day in a } \\
\text { specific region. A measure of order size. }\end{array}$ \\
\hline inventory & The total end-of-quarter inventory (in thousands) for Tristen Corporation. \\
\hline
\end{tabular}

Table 2. Analysis of Variable Summary Statistics

\begin{tabular}{|l|c|c|c|c|c|}
\hline \multicolumn{1}{|c|}{ Variable } & Obs & Mean & Std. Dev. & Min & \multicolumn{1}{c|}{ Max } \\
\hline leadtime & 2,323 & 7.025 & 2.709 & -1.042 & 17.190 \\
\hline leadtime $_{\mathrm{t}-1}$ & 2,323 & 7.046 & 2.723 & -1.041 & 17.266 \\
\hline daycount & 2,323 & 7.395 & 4.126 & 0.000 & 29.892 \\
\hline value & 2,323 & 5.668 & 2.106 & -2.625 & 12.773 \\
\hline units & 2,323 & -0.771 & 0.865 & -3.010 & 4.978 \\
\hline inventory & 2,323 & 365,649 & 83,788 & 252,802 & 519,328 \\
\hline
\end{tabular}

\section{Table 3. Table of Correlations}

\begin{tabular}{|l|c|c|c|c|c|c|}
\hline & leadtime & leadtime $_{t-1}$ & daycount & value & units & inventory \\
\hline leadtime & 1.000 & & & & & \\
\hline leadtime $t-1$ & $0.236^{* * *}$ & 1.000 & & & & \\
\hline daycount & $0.399^{* * *}$ & $0.071^{* * *}$ & 1.000 & & & \\
\hline value & $-0.054^{*}$ & $-0.062^{* *}$ & $0.185^{* * *}$ & 1.000 & & \\
\hline units & $-0.072^{* * *}$ & $-0.085^{* * *}$ & $0.361^{* * *}$ & $0.549^{* * *}$ & 1.000 & $-0.207^{* * *}$ \\
\hline inventory & 0.023 & 0.025 & $-0.166^{* * *}$ & $-0.244^{* * *}$ & 1.000 \\
\hline
\end{tabular}

${ }^{*} p<0.01,{ }^{* *} p<0.005,{ }^{* * *} p<0.001$ 
Table 4. ANCOVA Results

\begin{tabular}{|l|c|c|c|r|c|}
\hline \multicolumn{1}{|c|}{ Source } & Sum of Squares & df & Mean Square & F & Sig. \\
\hline model & 5148.056 & 5 & 1029.611 & 200.68 & 0.000 \\
postimp & 1461.835 & 1 & 1461.835 & 284.93 & 0.000 \\
value & 133.420 & 1 & 133.420 & 26.01 & 0.000 \\
units & 232.264 & 1 & 232.264 & 45.27 & 0.000 \\
daycount & 3919.520 & 1 & 3919.520 & 763.96 & 0.000 \\
inventory & 171.324 & 1 & 171.324 & 33.39 & 0.000 \\
\hline Residual & 11887.412 & 2317 & 5.131 & & \\
\hline N & 2323 & & & & \\
R2 (adj) & 0.3007 & & & & \\
\hline
\end{tabular}

through the development of an ANCOVA model to compare performance while simultaneously controlling for other potential performance-influencing factors. ANCOVA differs from more simple ANOVA approaches in that, in addition to allowing for the investigation of factor effects (as in ANOVA), it also facilitates the inclusion of continuous quantitative variables that might be related to the dependent variable. The intention of this augmentation is to provide a more accurate account of variance-source effects in the analysis (Neter et al. 1990).

An evaluation of means for transformed lead-time values indicates an average lead-time value of 8.18 (approximately 32.95 days untransformed) for the pre-deployment period versus an average lead-time value of 6.70 (approximately 23.20 days untransformed) in the post-deployment period. A simple unpaired t-test, assuming unequal variances, indicates that lead-time in the post-deployment period is significantly lower than in the pre-deployment period $(\mathrm{p}<0.001)$.

The ANCOVA model evaluates the same data, controlling for other potential explanatory variables. In the model, daily order volume (daycount), average daily order value (value), and daily average order volume (units) enter as continuous variables. Inventory is allowed to enter the model as a categorical variable, given that it represents a quarterly summary of inventory level for the firm. The variable of interest in this case is the indicator variable "postimp," which identified operational data collected from the pre- $($ postimp $=0)$ and post- (postimp $=1)$ deployment period. Results confirm a significant $(\mathrm{p}<0.001)$ difference in lead-time performance between the pre- and post-deployment periods and lend further support for H1. ANCOVA findings are presented in Table 4.

Hypothesis 2 proposes that a reinforcing cycle of system use and improvement may influence users over the long term as workers recognize performance improvements enabled by newly implemented system capabilities that reduce variability, bottlenecks, and waste. Through automated, informational, and transformational mechanisms, these system users (and superusers) are motivated to engage in deeper levels of use. Similarly, supervisory managers observe the benefits of the ERP and press for additional system use.

Both reinforcing behaviors (i.e., voluntary and mandated expansion) are examples of iteration in the process framework outlined in Figure 1 and are emblematic of continuous improvement driven by swift, even flow as well as a learningby-doing concept. This iteration is also characteristic of Gerwin's (1993) phasic model of observation, internalization, and application/involvement regarding the knowledge of newly introduced capabilities and processes. The analysis of learning-by-doing effects is frequently undertaken using learning curve models. These models generally posit that performance following implementation of a new process or technology will improve nonlinearly but monotonically with time or experience as a function of learning-by-doing (Dutton and Thomas 1984; Yelle 1979).

Testing of Hypothesis 2 commenced with the development of a model to capture the dynamic nature of lead-time performance over time. In order to distinguish between performance attributes of the pre- and post-deployment periods at Tristen, separate regressions were designed and performed for each era.

Visual inspection of the dependent variable (lead-time) data, a tactic recommended by Neter et al. (1990), suggested that nonlinear effects might be at work, particularly in the postdeployment period. Specifically, inspection suggested that performance did not improve strictly monotonically, but rather improved in the period immediately following ERP deployment, subsequently declining for a period of time before once again starting on an improvement trajectory. This improve-decline-improve pattern is consistent with findings 
from other ERP studies (Hitt et al. 2002; McAfee 2002). Whether this nonlinearity could be accounted for primarily by trends in control variable data or was in fact a largely timedependent phenomenon was unclear prior to model analysis.

Given observed nonlinearities and anticipated learning effects, we chose not to restrict the analysis to the strict monotonicity requirement of traditional learning curve models. Instead, we adopted a more flexible analytical approach. Following the examples set by recent process studies by Badiru (1992), Banker et al. (2001), and McAfee (2002), we included a quadratic time-based term in our model. While such specification does not preclude the modeling of strictly monotonic performance trends post-deployment of the ERP system, it provides the flexibility to capture alternative anomalies.

Introduction of the quadratic element to the model created additional challenges related to multicollinearity between the two time-based elements in the model. We address this by orthoganolizing the two variables through centering of the linear term before generating the quadratic (Neter et al. 1990). A check of variance inflation factors (VIF) indicates a satisfactory result with regard to mulitcollinearity. VIF values in the pre-deployment period average 5.10 , with no value exceeding 8.50. VIF values for the post-deployment period average 1.19 with no individual value exceeding 1.50 .

Analyses were designed that recognized the unique character of the data. Specifically, daily average order lead-time performance was available for a panel of three different operating regions in the pre- and post-deployment periods. Given the status of the data as a time-series, and the presence of a lagged dependent variable in the model, it was required that we appropriately test for the presence of autocorrelation and the possibility of its deleterious effect on the validity of findings (Armstrong 2001). Preliminary estimates of regionlevel models using OLS were tested using an alternative Durbin-Watson statistic that accommodates models where regressors are not strictly exogenous (as in cases where a regressor is a lagged dependent variable), as well as a Breusch-Godfrey Lagrange multiplier test for serial correlation in the error distribution (Wooldridge 2002). Neither test indicated the presence of significant autocorrelation in error terms in any region-level model, during either the pre- or post-deployment period. Individual regions displayed similar patterns of improvement. ${ }^{4}$

\footnotetext{
${ }^{4} \mathrm{~A}$ detailed analysis of differences in region-level performance is available from the first author.
}

Final analysis was conducted by fitting a cross-sectional timeseries linear model using feasible generalized least squares regression (GLS). Use of this analytic approach allowed us to simultaneously estimate a single lead-time improvement model for the firm, while still accounting for the uniqueness in region-level performance and the possibility that the error structure associated with each region differed. Despite previous assurances that autocorrelation did not represent a problem in estimating the model, we nonetheless allowed for the influence of separate autocorrelation coefficients associated with each region. Regressions were carried out in three steps. The first included all anticipated controls. The second and third steps included time-based linear and quadratic terms respectively serving as proxies of learning and process evolution effects (Banker et al. 2001; Gerwin 1993; McAfee 2002). Results of the analyses are presented in Table 5.

Significance of unrestricted models (i.e., those that include linear and nonlinear time indices) is evaluated using likelihood ratio tests. The addition of these terms is not found to be significant in the pre-deployment period, signifying a stable performance pattern (at least with respect to time). In contrast, such additions are found to be significant $(\mathrm{p}<0.001)$ in the post-deployment model, indicating a pattern of leadtime performance that changes with respect to time.

Support for $\mathrm{H} 2$ is provided by the significant log-likelihood increase in the post-deployment model upon the respective addition of each of these terms. Findings indicate a significant ongoing improvement dynamic in the key performance measure of order fulfillment lead-time; an effect that was not observed in the pre-deployment model. This finding is consistent with our visual interpretation of the data (as suggested by Figure 3), as well as with past models that have investigated ongoing learning and process change (Badiru 1992; Banker et al. 2001; McAfee 2002).

\section{Discussion}

Enterprise systems constitute a significant area of investment by global firms. They are also a source of major change for the firms that implement them. This paper has examined the influence of one such implementation on operational performance. It has moved beyond prior work by focusing theoretically on mechanisms at the process-level of the business unit, by illustrating the foundation of such dynamics qualitatively through case examination, and ultimately by analytically contrasting quantitative data relating to changes in performance dynamics over time. 


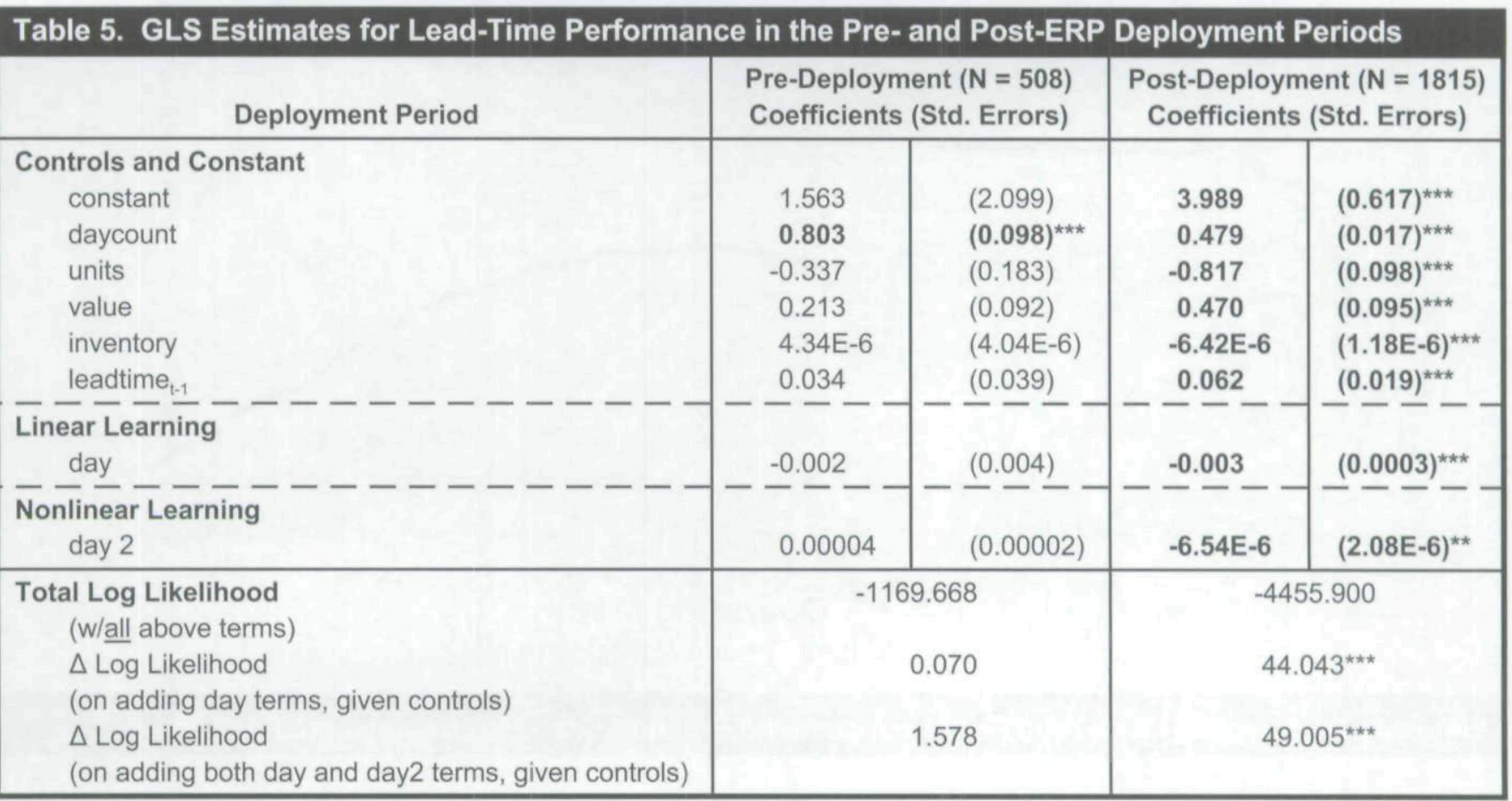

Overall our analysis of a key metric driving the ERP initiative at Tristen (i.e., order lead-time) shows a distinct shift in the pattern of performance after ERP deployment in support of our first hypothesis (H1). From a broad perspective, the evidence presented here can be viewed as supporting prior research in the enterprise systems domain (e.g., Hitt et al. 2002; McAfee 2002) in that it reinforces the notion that these systems can enable significant improvements in firm performance upon deployment. Our findings also provide evidence that the shifts in performance trends predicted by the theory of swift, even flow (and anticipated in the present ERP case) can be measured objectively if sufficient care is taken to account for associated operational factors. Our results illustrate that improvement trends can persist over time even after accounting for reasonable alternative explanations for process performance (e.g., changes in inventory levels, order and business scale, and autoregressive trends). Overall we find support for our hypothesis regarding the dynamics of ongoing learning-based ERP benefits (H2).

\section{Limitations}

The limitations of this study should be kept in mind when interpreting the results. First, our research is restricted to a single detailed case investigation. Although not an uncommon methodology for in-depth qualitative and quantitative examinations, such a focus does limit the generalizability of our results across dissimilar settings. Second, the data do not exhaustively cover the entire study period. Characteristics of the firm's data conversion strategy led us to eliminate data for the 3 months prior to deployment of the ERP applications. It is, therefore, possible that actual initial performance gains differ from those presented as part of this analysis. Future research should seek performance data that is not subject to the limitations of the current data set.

Finally, this study uses a single performance measure to gauge an information technology's influence on operational effectiveness. Since order lead-time was a key performance measure motivating Tristen's implementation (as documented in their initial business case and consistent with their strategic goal of improved service), our focus on this particular measure is justified in the present case. Nevertheless, other performance measures might certainly be worth investigating: (1) if justified by the business case and (2) provided such data is available.

In fact, a focus on alternate operational performance measures (such as fill rates, inventory turns, etc.) may be justified in cases where the firm's goal is operational cost reduction (as fitting a low-price focused strategy). Such investigations might suggest similar or very different patterns of performance improvement as compared to those observed in this 


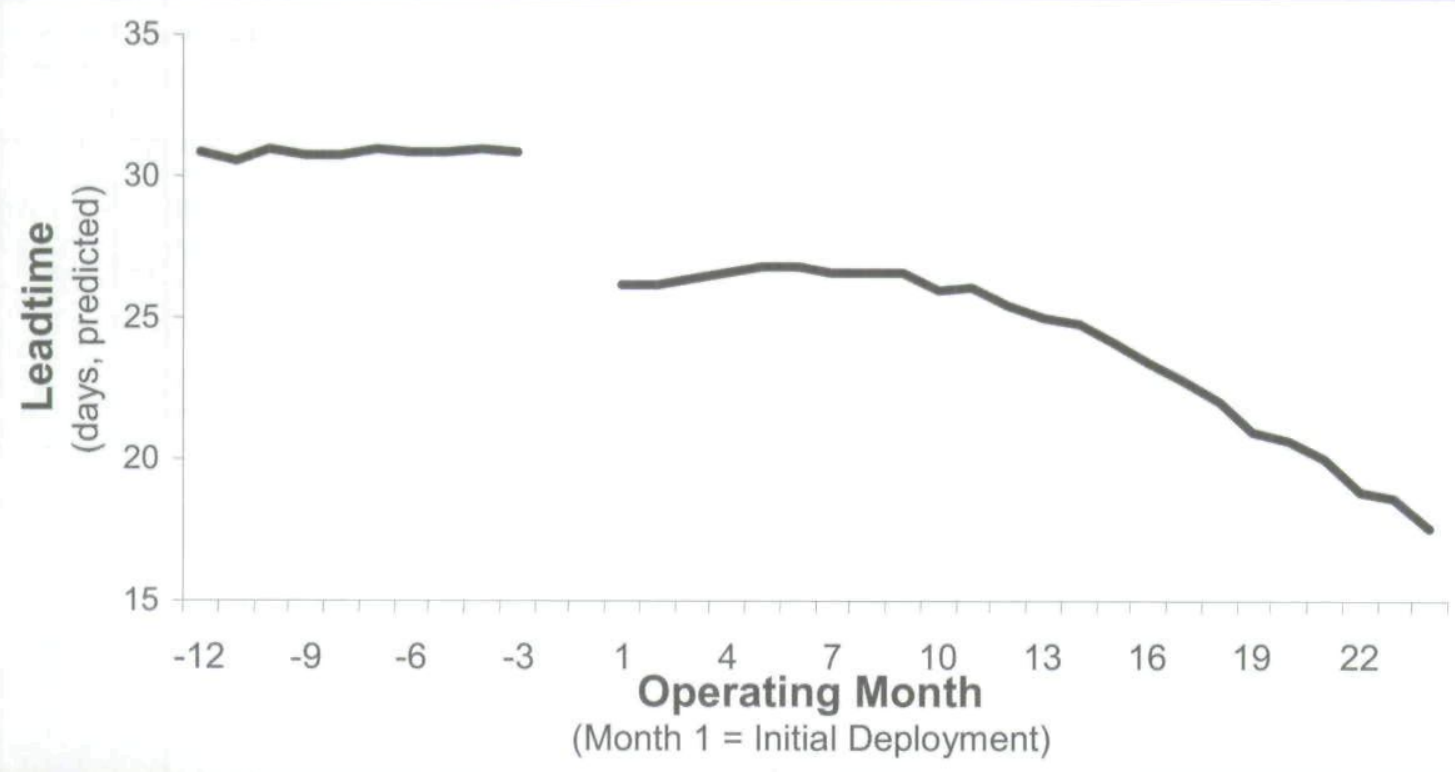

Figure 4. Prototypical Lead-Time Performance in the Pre- and Post-ERP Deployment Periods

study. Regardless, researchers should be cautious to ensure that the selection of performance measures truly characterizes the specific interests of the firms investigated in order to avoid spuriosity and general difficulties in interpretability.

\section{Implications}

Several interesting managerial and theoretical implications emerge from our findings. As a first step toward developing this understanding, we proceeded with an evaluation of prototypical lead-time values for the pre- an post-deployment periods. Prototypical lead-time values are generated using median pre- and post-deployment values for daycount, units, value, and inventory, along with median monthly values for the lagged dependent variable. A plot of these prototypical values is provided in Figure 4.

Figure 4 illustrates results applicable to both Hypothesis 1 and Hypothesis 2. Related to Hypothesis 1, the prototypical plot illustrates an immediate improvement in order lead-time performance coinciding with ERP deployment. For example, a comparison of lead-time performance for the month immediately preceding and the month immediately following ERP deployment reveals an improvement of approximately 4.76 days ( 30.91 days pre-deployment versus 26.15 days postdeployment). Average prototypical lead-time performance for the full pre-deployment period is estimated to be 30.81 days, compared with average prototypical lead-time performance of

\subsection{5 days in the post-deployment period.}

From a managerial perspective, case examination at the end of the study period showed that the bottom-line impact of the lead-time improvements was significant for Tristen Corporation. At $\$ 4$ billion in annual revenue, the firm generated approximately $\$ 11$ million in sales every day. By shortening the order-to-cash business cycle, Tristen stood to release valuable working capital for reinvestment or return to shareholders. Careful review of Figure 4 suggests an improvement in order lead-time, a critical component of the order-to-cash business cycle, from approximately 30.81 days in the predeployment period, to approximately 17.52 days at the end of the study period. At $\$ 11$ million per day, this 13.29 day improvement potentially yielded more than $\$ 146$ million (13.29 days at $\$ 11$ million per day) in released working capital for a $\$ 50$ million dollar investment in ERP.

By the end of the study period, revenue-adjusted inventory levels also remained below historic averages as Tristen Corporation continued to maintain significant improvements in lead-time performance. This inventory reduction represents an additional release of working capital relative to the pre-ERP context. Given these revenue-adjusted inventory levels, we surmise that from an organizational learning perspective, the firm had learned enough about the new systems to work well in the absence of inventory buffers. Thus, it was able to reduce inventory levels without unduly harming leadtime performance. 
Taking into consideration the general stagnation (or even slight worsening) of lead-times in the 6 months immediately following deployment, and related to Hypothesis 2, the prototypical plots illustrated in Figure 4 show the same kind of improve-decline-improve pattern identified in early visual inspections and in other, related research (e.g., Hitt et al. 2002; McAfee 2002). More important, following this initial 6 month period, a pattern of continued lead-time improvement is observable through the end of the study period. In that this continued period of improvement is not simply linear, but notably nonlinearly increasing (as exemplified by our analysis), such a trend may not only be indicative of continued learning but also of an evolution in learning capabilities themselves (i.e., learning to learn).

Since individual and business unit experience not only supports improvements in practice but may also support improvements in exploration tactics (Buck and Cheng 1993; Eyring et al. 1993), the empirical observations of such dynamics may not be rare in similar settings. Although this trend must eventually taper off ( $\mathrm{He}$ and Wong 2004; McGrath 2001), such early stage acceleration and continued gains provides an intriguing contrast to traditional monotonic views of learning.

More specifically, our findings might indicate that the application of sigmoidal learning curve specifications (slow to start, heightened, and then ultimately asymptotically marginal) may be more appropriate for model consideration. The question then becomes one of how to tap into the learning acceleration phenomenon as early and effectively as possible. While such an issue suggests an intriguing space for future research, it also challenges managers to appreciate the kinds of steps they might take to foster the acceleration of experience-based learning. Finally, it may suggest a new emphasis on better identifying and taking advantage of opportunities in IT-driven continuous improvement efforts, as supported by the present theoretical application of the theory of swift, even flow.

The fact that our analysis revealed continued lead-time performance improvements regardless of inventory anomalies is a testament to how the effective use of ERP in cultures of continuous improvement can breed learning benefits that offer not only one-shot tactical appeal, but also potentially strategic appeal due to ongoing dynamics and gains. In fact, the detection of such an ongoing shift in organizational learning due to ERP deployment suggests that, well in line with our application of swift, even flow, such systems can provide the catalyst for the kind of flexibility often discussed as a competitive advantage among firms. While the catalyst itself may be imitable, the nuances of such dynamics are almost certainly idiosyncratic and thus strategically relevant. A worthy pursuit for researchers would be to delineate the extent to which gains made possible through swift, even flow dynamics are in fact deemed strategic as opposed to purely tactical. Such a distinction could be invaluable for managers considering the extent to which they wish to engage (i.e., invest) in ITsupported continuous improvement programs.

In conclusion (and regardless of research motivation), perhaps the most critical methodological implication of our study is the obvious need for researchers to begin examining not only point estimates in time but trends over time, specifically along operational-level measures for which implementations are anticipated to have significant and potentially strategic impacts. Without a concerted focus on targeted process effects, the benefits accrued by such initiatives may be difficult to reasonably assess. From a methodological perspective, this conclusion adds greater credence to the call for more targeted, in-depth research in measuring IT benefits (Brynjolfsson and Hitt 1997). Until such efforts become a mainstay of technology examination, the gap between research and practice has little hope of becoming less substantial. When longitudinal approaches, even at a limited level, do become more common, they will no doubt open doors to practice and new theory that are difficult to anticipate based on current knowledge. Coupled with a willingness of researchers to seek out guidance from areas external to their own knowledge domain, as we have attempted here, this, albeit humble, approach presents perhaps the most valuable of opportunities.

\section{Acknowledgments}

The authors would like to acknowledge the generous financial support of the Harvard Business School Division of Research, and the substantial contributions of our anonymous reviewers.

\section{References}

Adler, P. S., and Clark, K. B. "Behind the Learning Curve: A Sketch of the Learning Process," Management Science (37:3), March 1991, pp. 267-281.

AMR "The Report on Enterprise Management," Report, AMR Research, Inc., 2001.

Argote, L., and Epple, D. "Learning Curves in Manufacturing," Science (247), 1990, pp. 920-924.

Armstrong, J. S. (ed.). Principles of Forecasting, Kluwer Academic Publishers, Boston, 2001.

Austin, R. D., and Cotteleer, M. J. "Current Issues in IT: Enterprise Resource Planning and Ecommerce," research presentation at the Harvard Business School, Boston, MA, 1999. 
Austin, R. D., and Cotteleer, M. J. "Current Issues in IT: Enterprise Resource Planning and Ecommerce," research presentation at the Harvard Business School, Boston, MA, 2001.

Austin, R. D., and Nolan, R. "How to Manage ERP Initiatives," Working Paper, Harvard Business School, Boston, 1998.

Badiru, A. B. "Computational Survey of Univariate and Multivariate Learning Curve Models," IEEE Transactions on Engineering Management (39:2), May 1992, pp. 176-189.

Banker, R. D., Field, J. M., and Sinha, K. K. "Work-Team Implementation and Trajectories of Manufacturing Quality: A Longitudinal Field Study," Manufacturing \& Service Operations Management (3:1), Winter 2001, pp. 25-42.

Banker, R. D., and Kauffman, R. J. "The Evolution of Research on Information Systems: A Fiftieth Year Survey of the Literature in Management Science," Management Science (50:3), 2004, pp. 281-298.

Banker, R. D., and Kauffman, R. J. "Strategic Contributions of Information Technology: An Empirical Study of ATM Networks," in Proceedings of the $9^{\text {th }}$ International Conference on Information Systems, J. I. DeGross and M. H. Olson (eds.), Minneapolis, MN, November 30-December 3, 1988, pp. 141-150.

Banker, R. D., Kauffman, R. J., and Morey, R. C. "Measuring Gains in Operational Productivity from Information Technology: A Study of the Positron Deployment at Hardee's Inc.," Journal of Management Information Systems (7:2), 1990, pp. 29-54.

Bendoly, E. "ERP Systems and Supply Chain Technologies: A Caveat for B2B E-Procurement," FedEx White Paper Series, Memphis, TN, 2001, pp. 28-36.

Bendoly, E., and Cotteleer, M. J. "Resonant Dissonance: Investigating Sources of Lagged Operational Variance Following LargeScale Centralized System Deployment," in Proceedings of the $9^{\text {th }}$ Conference on Information Systems and Technology (CD-ROM), Denver, CO, October 23-24, 2004.

Bendoly, E., and Kaefer, F. "Business Technology Complementarities: Impact of the Presence and Timing of ERP on B2B ECommerce Technology Efficiencies," Omega (32:5), 2004, pp. 395-405.

Bendoly, E., and Schoenherr, T. "ERP System and Implementation Process Benefits: Implications for B2B E-Procurement," International Journal of Operations and Production Management (25:4), 2005, pp. 304-319.

Box, G. E. P., and Cox, D. R. "An Analysis of Transformations," Journal of the Royal Statistical Society (Series B:26), 1964, pp. 211-243.

Brynjolfsson, E., and Hitt, L. M. "Computing Productivity: Are Computers Pulling Their Weight?," MIT and Wharton Working Paper, Massachusetts Institute of Technology, Cambridge, MA, 1997.

Brynjolfsson, E., and Hitt, L. M. "Paradox Lost: Firm-Level Evidence on the Returns to Information Systems Spending," Management Science (42:4), April 1996, pp. 541-558.

Buck, J. R., and Cheng, S. J. "Instructions and Feedback Effects on Speed and Accuracy with Different Learning Curve Models," IIE Transactions (25:6), 1993, pp. 34-37.
Cattani, K. D., and Souza, G. C. "Inventory Rationing and Shipment Flexibility Alternatives for Direct Market Firms," Production and Operations Management (11:4), 2002, pp. 441-457.

Chen, I. J. "Planning for ERP Systems: Analysis and Future trends," Business Process Management Journal (7:5), 2001, pp. 374-386.

Cheng, F., Ettl, M., Lin, G., and Yao, D. D. "Inventory-Service Optimization in Configure-to-Order Systems," Manufacturing \& Service Operations Management (4:2), 2002, pp. 114-132.

Chew, W. B., Leonard-Barton, D., and Bohn, R. E. "Beating Murphy's Law," Sloan Management Review (32:3), Spring 1991, pp. 5-16.

Conway, R., Maxwell, W., McClain, J. O., and Thomas, L. J. "The Role of Work-in-Process Inventory in Serial Production Lines," Operations Research (36:2), 1988, pp. 229-241.

Cotteleer, M. J. "An Empirical Study of Operational Performance Convergence Following Enterprise Systems Deployment," Production and Operations Management (15:1),Spring 2006, pp. 74-87.

Davenport, T. Mission Critical: Realizing the Promise of Enterprise Systems, Harvard Business School Press, Boston, MA, 2000.

Davenport, T. Process Innovation: Reengineering Work through Information Technology, Harvard Business School Press, Boston, 1993.

Davenport, T. "Putting the Enterprise into the Enterprise System," Harvard Business Review (76:4), July/August 1998, pp. 121-131.

Davidow, W., and Malone, M. The Virtual Organization, Harper Collins, New York, 1992.

Dutton, J., and Thomas, A. "Treating Progress Functions as a Managerial Opportunity," Academy of Management Review (9:2), 1984, pp. 235-247.

Epple, D., Argote, L., and Murphy, K. "An Empirical Investigation of the Microstructure of Knowledge Acquisition and Transfer Through Learning by Doing," Operations Research (44:1), January-February 1996, pp. 77-86.

Escalle, C., and Cotteleer, M. "Enterprise Resource Planning (ERP)," Technology Note, Harvard Business School, Boston, MA, 1999.

Eyring, J. D., Johnson, D. S., and Francis, D. J. “A Cross-Level Unit-of-Analysis Approach to Individual Differences in Skill Acquisition," Journal of Applied Psychology (78:5), 1993, pp. 805-814

Gerwin, D. "Manufacturing Flexibility: A Strategic Perspective," Management Science (39:4), 1993, pp. 395-410.

Goldratt, E. The Goal: A Process of Ongoing Improvement ( $2^{\text {nd }}$ ed.), North River Press, Great Barrington, MA, 1992.

Gruber, H. "The Learning Curve in the Production of Semiconductor Memory Chips," Applied Economics (24), 1992, pp. 885-894.

Gruber, H. "The Yield Factor and the Learning Curve in Semiconductor Production," Applied Economics (26), 1994, pp. 837-843.

Gudum, C. K. "Managing Variability in a Supply Chain: An Inventory Control Perspective," Statistics Group Working Paper, Copenhagen Business School, Copenhagen, 2002. 
Hayes, R. H., Wheelwright, S. C., and Clark, K. B. Dynamic Manufacturing: Creating the Learning Organization, The Free Press, New York, 1988.

He, Z., and Wong, P. "Exploration vs. Exploitation: An Empirical Test of the Ambidexterity Hypothesis," Organization Science (14:4), 2004, pp. 481-494.

Heuts, R., and Deklein, J. "An (S-Q) Inventory Model with Stochastic and Interrelated Lead Times," Naval Research Logistics (42), 1995, pp. 839-859.

Hitt, L. M., Wu, D. J., and Zhou, X. "Investment in Enterprise Resource Planning," Journal of Management Information Systems (19:1), Summer 2002, pp. 71-98.

Hult, G. T., Ketchen, D. J., and Nichols, E. L. "An Examination of Cultural Competitiveness and Order Fulfillment Cycle Time Within Supply Chains," Academy of Management Journal (45:3), June 2002, pp. 577-586.

Jacobs, F. R., and Bendoly, E. "Enterprise Resource Planning: Developments and Directions for Operations Management Research," European Journal of Operational Research (146:2), April 2003, pp. 233-240.

Kannan, V. R., and Palocsay, S. W. "Cellular vs. Process Layouts: An Analytic Investigation of the Impact of Learning on Shop Performance," Omega (27), 1999, pp. 583-592.

Kauffman, R. J., and Kriebel, C. H. "Modeling and Measuring the Business Value of Information Technology," in Measuring the Business Value of Information Technologies, P. Strassmann, P. Berger, E. B. Swanson, C. H. Kriebel, and R. J. Kauffman (eds.), ICIT Press, Washington DC, 1988, pp. 134-147.

King, J. L., and Kraemer, K. L. "Implementation of Strategic Information Systems," in Information Technology and Management Strategy, K. C. Laudon and J. A. Turner (eds.), Prentice Hall, Englewood Cliffs, NJ, 1989, pp. 58-73.

Kling, R. "Computerization and Social Transformations," Science, Technology, \& Human Values (16:3), 1991, pp. 342-367.

Lee, A. "Editors Comments: Researchable Directions for ERP and Other New Information Technologies," MIS Quarterly (24:1), March 2000, pp. iii-viii.

Mabert, V. A., Soni, A., and Venkataramanan, M. A. "Enterprise Resource Planning Survey of U.S. Manufacturing Firms," Production and Inventory Management Journal (41:2), Second Quarter 2000, pp. 52-58.

Markus, M. L., Tanis, C., and van Fenema, P. C. "Multisite ERP Implementations," Communications of the ACM (43:4), April 2000, pp. 42-46.

McAfee, A. "The Impact of Enterprise Information Technology Adoption on Operational Performance: An Empirical Investigation," Production and Operations Management (11:1), Spring 2002, pp. 1-21.

McGrath, R. G. "Exploratory Learning, Innovative Capacity and Managerial Oversite," Academy of Management Journal (44:1), 2001, pp. 118-131.

Mooney, J. G., Gurbaxani, V., and Kraemer, K. L. "A Process Oriented Framework for Assessing the Business Value of Information Technology," in Proceedings of the $16^{\text {th }}$ Inter- national Conference on Information Systems, J. I. DeGross, G. Ariav, C. Beath, R. Hoyer, and C. Kemerer (eds), Amsterdam, December 10-13, 1995, pp. 17-28.

Mukhopadhyay, T., and Cooper, R. B. "Impact of Management Information Systems on Decisions," Omega (20:1), 1992, pp. $37-49$.

Neter, J., Wasserman, W., and Kutner, M. H. Applied Linear Statistical Models: Regression, Analysis of Variance, and Experimental Design ( $3^{\text {rd }}$ ed.), ), Richard D. Irwin, Inc., Boston, MA, 1990.

Powell, S. G., and Schultz, K. L. "Throughput in Serial Lines with State-Dependent Behavior," Management Science (50:8), 2004, pp. 1095-1105.

Reid, L. "Continuous Improvement through Process Management," Management Accounting (74:3), 1992, pp. 37-44.

Royston, P. "Approximating the Shapiro-Wilk W-Test for NonNormality,” Statistics and Computing (2), 1992, pp. 117-119.

SAP. "SAP 2001 Annual Report: With Open Technology, We Help Our Customers Foster Growth, Innovation and Value...," SAP AG, Walldorf, Germany, 2001 (available online at http:// www.sap.com/company/investor/reports/annualreport/2001/ind ex.epx).

Scheer, A. W., and Habermann, F. "Making ERP A Success," Communications of the ACM (43:4), April 2000, pp. 57-61.

Schmenner, R. W., and Swink, M. L. "On Theory in Operations Management," Journal of Operations Management (17:1), December 1998, pp. 97-114.

Schultz, K. L., Juran, D. C., Boudreau, M. C., McClain, J. O., and Thomas, L. J. "Modeling and Worker Motivation in JIT Production Systems," Management Science (44:21), 1998, pp. 1595-1607.

Song, J., and Xu, S. H. "Order-Fulfillment Performance Measures in an Assemble-to-Order System with Stochastic Leadtimes," Operations Research (47:1), 1999, pp. 131-149.

Stalk, G., and Hout, T. M. "Competing Against Time," Research Technology Management (33:2), March-April 1990, pp. 19-25.

Stein, E. W., and Zwass, V. "Actualizing Organizational Memory with Information Systems," Information Systems Research (6:2), June 1995, pp. 85-117.

Upton, D. A., and McAfee, A. P. "A Path-Based Approach to Information Technology in Manufacturing," International Journal of Technology Management (20:3,4), 2000, pp. 354-372.

Willcocks, L. P., and Sykes, R. "The Role of the CIO and IT Function in ERP," Communications of the ACM (43:4), April 2000, pp. 32-38.

Wooldridge, J. Introductory Econometrics: A Modern Approach Thomson/South-Western, Mason, OH, 2002.

Yelle, L. E. "The Learning Curve: Historical Review and Comprehensive Survey," Decision Sciences (10), 1979, pp. 302-328.

Yusuff, R. M. "Manufacturing Best Practices of the Electric and Electronic Firms in Malaysia," Benchmarking: An International Journal (11:4), 2004, pp. 361-369.

Zhu, D., Prietula, M. J., and Hsu, W. L. "When Processes Learn: Steps Toward Crafting an Intelligent Organization," Information Systems Research (8:3), 1997, pp. 302-317. 
Zipkin, D. "Inventory Service-Level Measures: Convexity and Approximation," Management Science (32:8), 1986, pp. 975-983.

Zuboff, S. In the Age of the Smart Machine, Basic Books, New York, 1988.

\section{About the Authors}

Mark Cotteleer is an assistant professor at the College of Business Administration at Marquette University. His research focuses on the impact of enterprise-level information technologies on operational performance, moderators of implementation success, and the quantification and delivery of value through information systems implementation. He has authored papers, several best-selling teaching cases, and technology notes on these topics, and has presented at numerous industry and academic conferences. Prior to academia, Dr. Cotteleer consulted for Ernst \& Young, LLP, where he led business process reengineering teams in the design and development of business processes around the implementation of ERP software packages, and for Andersen Consulting (now Accenture), focusing on the design, development, and implementation of custom order management and production planning information systems. Dr. Cotteleer earned his DBA at the Harvard Business School, specializing in Technology and Operations Management and Management
Information Systems. He holds a Master of Business Administration, specializing in Operations Management, and a Master of Science in Industrial Engineering from the University of Michigan.

Elliot Bendoly, editor of Strategic ERP Extension and Use (Stanford Press, 2005), is a faculty member in Decision and Information Analysis at Emory University's Goizueta Business School. Prior to academia, he worked as a research engineer for Intel Corporation. He holds a Ph.D. in the fields of Operations Management and Decision Sciences from Indiana University. Along with these specializations, his academic background includes an Information Systems orientation including database, ERP, and knowledge management foci. During this time he served as an instructor and developer of SAP implementation and ABAP/4 programming curriculum. More recently he has been involved with coursework on IT supported service operations and supply chain management. His research has been published in a wide range of elite academic journals including the Journal of Operations Management, Production and Operations Management, MIS Quarterly, Journal of Applied Psychology, Journal of Service Research, European Journal of Operational Research, and International Journal of Operations and Production Management. His current research focuses on operational issues in IT utilization and organizational behavioral dynamics. 